\title{
L'élection au village dans la France du XIXe siècle. Réflexions à partir du cas finistérien
}

The election in the village in France of the $19^{\text {th }}$ century. Reflexions from the finistérien case

Die Wahl im Dorf im Frankreich des 19. Jahrhunderts. Beobachtungen ausgehend vom Fall Finistère

Laurent Le Gall

\section{OpenEdition}

Journals

Édition électronique

URL : http://journals.openedition.org/rh19/4150

DOI : $10.4000 /$ rh 19.4150

ISSN : $1777-5329$

Éditeur

La Société de 1848

Édition imprimée

Date de publication : 13 novembre 2011

Pagination : 17-39

ISSN : 1265-1354

\section{Référence électronique}

Laurent Le Gall, « L'élection au village dans la France du XIXe siècle. Réflexions à partir du cas

finistérien », Revue d'histoire du XIXe siècle [En ligne], 43 | 2011, mis en ligne le 10 juillet 2015, consulté le 01 mai 2019. URL : http://journals.openedition.org/rh19/4150 ; DOI : 10.4000/rh19.4150 


\section{LAURENT LE GALL}

\section{L'élection au village dans la France du XIX siècle. Réflexions à partir du cas finistérien}

À en croire certaines publications, village et élection font toujours bon ménage. Consacré à la politisation des paysans au XIX ${ }^{e}$ siècle, l'article synthétique que fit paraitre Gilles Pécout en 1994 soulignait combien de nouvelles interrogations sur le vote alimentaient la «réouverture d'un vieux dossier $»^{1}$. Vieux dossier, en effet, que celui qui, depuis les grandes thèses d'inspiration labroussienne, n'avait cessé de s'épaissir après que les mondes ruraux eurent été transformés en des espaces historiographiques d'observation intensive ${ }^{2}$ : «Longtemps, l'élection constitua pour les historiens des campagnes le seul élément d'appréciation de la vie politique et, partant, le suffrage universel fut considéré comme l'indice cardinal de la politisation paysanne ${ }^{3}$. On ne saurait mieux résumer la situation. La convergence éditoriale du début des années 1990 qui vit Raymond Huard ${ }^{4}$, Alain Garrigou ${ }^{5}$, Pierre Rosanval$\operatorname{lon}^{6}$ et Michel Offerlé , chacun dans son champ disciplinaire, aborder ce que déposer (ou non) un bulletin dans une urne avait voulu dire, ouvrait sur de nouveaux horizons. Étaient plus ou moins passés au crible - même si cela était en creux - les impasses et les dividendes d'une histoire classique du vote portée par ceux qui interprétaient l'entreprise siegfriedienne d'élucidation du suffrage sous l'angle de la seule pétrification des opinions ${ }^{8}$. Le citoyen n'était plus cet acquis révolutionnaire capable d'évoluer à l'intérieur d'un

1. Gilles Pécout, "La politisation des paysans au XIX ${ }^{e}$ siècle. Réflexions sur l'histoire politique des campagnes françaises", Histoire et Sociétés Rurales, n 2, 1994, p. 106.

2. Jean-Luc Mayaud, "Une histoire rurale éclatée (1945-1993) ? La France du XIXe siècle», in Alain Faure, Alain Plessis et Jean-Claude Farcy [dir.], La terre et la cité. Mélanges offerts à Philippe Vigier, Grâne, Créaphis, 1994, p. 21-31; Susan Carol Rogers, 'Natural histories : The Rise and Fall of French Rural Studies', French Historical Studies, XIX, 2 (1995), p. 383.

3. Gilles Pécout, "La politisation des paysans...", loc. cit., p. 106.

4. Raymond Huard, Histoire du suffrage universel (1848-1946), Paris, Aubier, 1991.

5. Alain Garrigou, Le vote et la vertu. Comment les Français sont devenus électeurs, Paris, Presses de la Fondation Nationale des Sciences Politiques, 1992; réédition revue et augmentée : Histoire sociale du suffrage universel en France, 1848-2000, Paris, Le Seuil, 2002. 1992.

6. Pierre Rosanvallon, Le sacre du citoyen. Histoire du suffrage universel en France, Paris, Gallimard,

7. Michel Offerlé, Un homme, une voix? Histoire du suffrage universel, Paris, Gallimard, 1993.

8. René Rémond, "L'apport des historiens aux études électorales», Vingtième Siècle. Revue d'histoire, n 8, 1985, p. 107-116; "Les élections», in René Rémond [dir.], Pour une histoire politique, Paris, Le 
espace dont les règles du jeu s'imposaient suffisamment - voire immédiatement - à lui pour qu'il se transforme en un acteur éminemment rationnel. La civilisation électorale supposait qu'elle soit considérée comme le produit d'une acculturation progressive, et toujours conflictuelle, d'individus hétéronomes appelés à être de plus en plus continûment des mandants ${ }^{9}$. Le vote n'était qu'une des manifestations d'un ordre démocratique capable de générer des formes alternatives et/ou connexes (manifestations, banquets, fêtes, etc.) susceptibles d'opérer une dilatation et un approfondissement dudit ordre. L'élection étant une opération à plusieurs inconnues, les «explications du vote» faisaient donc de ce dernier tout autant une énigme qu'une évidence.

En 1994, Gilles Pécout dessinait trois axes de recherche pour celles et ceux qui, dans le sillage de l'article de Maurice Agulhon ou contre certaines de ses analyses ( 1848 , le suffrage universel et la politisation des campagnes françaises ${ }^{10}$ ), entendaient poursuivre la réflexion : les articulations entre modes d'acquisition du suffrage censitaire et passage au suffrage universel masculin; les relations entre appropriation individuelle du droit de vote et constitution d'un champ politique spécifique organisé par et autour de ses professionnels; les liens entre participation électorale et nationalisation de la vie publique. Une quinzaine d'années après, village et élection continuent de fraterniser dans certains travaux qui auscultent la France du XIX siècle, même si l'objet est fréquemment abordé par la bande. En filigrane dans la synthèse que Jean-Pierre Jessenne a consacrée à l'histoire des campagnes ${ }^{11}$, il est, dans la thèse de Corinne Marache sur les métamorphoses de la Double en Périgord, un des éléments d'une coda qui fait de la mobilisation électorale un indicateur de la modernisation $\mathrm{du}$ " pays» monographié ${ }^{12}$. Plus récemment encore, il apparaît, tout au long de l'ouvrage de Chloé Gaboriaux consacré aux relations qu'entretenaient les républicains avec le bonapartisme rural, à la manière d'un trompe-l'œil indiciaire permettant à l'auteur d'analyser comment la commune, conçue comme une entité politique, est devenue un enjeu idéologique entre des forces concurrentes ${ }^{13}$. Qu' elle serve de déclinaison à ce que des décennies d'accumulation scientifique de matériaux ont produit ou de conformation à quelques grands modèles d'interprétation du vote dont

Seuil, 1988, p. 33-48. Pour une mise au point, on se référera à l'ouvrage de Pierre Favre, Naissances de la science politique en France (1870-1914), Paris, Fayard, 1989, p. 235-306.

9. Le vote fut aussi affaire de mobilisation des représentations et d'inculcation civique. $C f$. les pages que consacre Pierre Rosanvallon à la ferveur démopédique dans Le sacre du citoyen..., op. cit., p. 355-372.

10. Maurice Agulhon, "1848, le suffrage universel et la politisation des campagnes françaises", in Histoire vagabonde, tome 3 : La politique en France, d'hier à aujourd'hui, Paris, Gallimard, 1996, p. 61-82.

11. Jean-Pierre Jessenne, Les campagnes françaises entre mythe et histoire (XVIII ${ }^{e}-X X I^{e}$ siècle), Paris, Armand Colin, 2006, p. 89-99 et 190-194.

12. Corinne Marache, Les métamorphoses du rural. L'exemple de la Double en Périgord (1830-1939), Paris, Comité des Travaux Historiques et Scientifiques, 2006, p. 403-406.

13. Chloé Gaboriaux, La République en quête de citoyens. Les républicains français face au bonapartisme rural (1848-1880), Paris, Presses de Sciences Po, 2010, ch. 4, en particulier p. 187-233. 
la socio-histoire a renouvelé les approches depuis deux décennies ${ }^{14}$, l'élection au village s'écrit toujours, bon gré mal gré, au risque de la répétition. On ne proposera pas ici de compiler une bibliographie à ce point pléthorique qu'elle enjoint certains auteurs à utiliser, lorsqu'ils y sont confrontés, l'expression de «bibliographie sélective». Foin de bilan historiographique, donc, à l'instar des inventaires méticuleux et roboratifs qui traitèrent, par exemple, de la question pour la Seconde République ${ }^{15}$. L'on se bornera plus modestement, à partir de la «digestion» d'un travail qui nous aura occupé plusieurs années ${ }^{16}$, à esquisser quelques pistes de réflexion. Elles n'entendent pas invalider telle ou telle approche (parce que l'une obéirait plutôt à une logique nomologique et l'autre plutôt à une logique idiographique), mais espèrent contribuer modestement à l'affinement de certaines analyses qui font de l'élection avant toute chose un espace de relations sociales.

\section{LE VILLAGE ET L'ÉLECTION : QUELLE PERTINENCE POUR QUEL OBJET?}

Parce que la France fut, d'après les catégories en cours, un pays peuplé majoritairement de ruraux jusqu'au début des années 1930, l'électeur a été préférentiellement conçu dans nombre d'études électorales comme cet individu inscrit définitivement dans l'aire de sa communauté villageoise sans que son appartenance (en termes de degré ou d'effectivité) à cette communauté, tout aussi formelle qu'imaginaire d'ailleurs ${ }^{17}$, ne soit clairement discutée. Le village - entendu, le plus généralement, en tant que commune - aurait été ainsi, dans le cadre d'un ordre démocratique qui se serait construit sur les rapports conflictuels et ambigus du centre et de la périphérie, du local et du national (des catégories pratiques car suffisamment vagues et génériques pour passer sans coup férir du particulier au général et du général au particulier), une sorte de prisme privilégié facilitant la compréhension d'une

14. Cf. la mise au point de Michel Offerlé, «De l'histoire électorale à la socio-histoire des électeurs", Romantisme, n 135 : L'élection au XIXe siècle, 2007, p. 61-73. Du même auteur : "Capacités politiques et politisations : faire voter et voter, XIXe-XX siècles (1)", Genèses, nº 67, juin 2007, p. 131-149; "Capacités politiques et politisations : faire voter et voter, XIXe-XXe siècles (2) », Genèses, $n^{\circ} 68$, septembre 2007, p. 145-160. On se reportera aussi aux pages que consacre Yves Déloye à la civilisation électorale dans sa Sociologie historique du politique, Paris, La Découverte, 2003 (1 ${ }^{\text {re édition }}$ 1997), p. 79-104.

15. Deux états des lieux d'une grande richesse : Raymond Huard, "Le "suffrage universel" sous la Seconde République. État des travaux, questions en attente", Revue d'Histoire du XIXe siècle, $\mathrm{n}^{\circ} 14$, 1997, p. 51-72; Pierre Lévêque, «Les campagnes françaises et la Deuxième République : cinquante ans d'historiographie", Revue d'Histoire du XIX'e siècle, n 14, 1997, p. 73-87.

16. Laurent Le Gall, L'électeur en campagnes dans le Finistère. Une Seconde République de Bas-Bretons, Paris, La Boutique de l'Histoire/Les Indes savantes, 2009.

17. Cf. François Ploux, "Production et recomposition des identités villageoises en France de la monarchie de Juillet aux années 1930 ", in Jean-Luc Mayaud et Lutz Raphael [dir.], Histoire de l'Europe rurale contemporaine. Du village à l'État, Paris, Armand Colin, 2006, p. 39-56. 
réalité sociale que l'utilisation d'autres échelles empêcherait de scruter ${ }^{18}$. En faisant florès à la suite du titre du maître-livre que Maurice Agulhon consacra aux populations du Var sous la Seconde République ${ }^{19}$, la locution «au village" ajoutée à un titre de chapitre ou à une contribution devint sinon une marque de fabrique, tout au moins un haut lieu de la description des pratiques politiques à l'intérieur d'un cadre d'autant mieux circonscrit qu'il était aussi auréolé de la postérité d'une œuvre. En obtenant ce succès scientifique et éditorial, le village se mua en une réalité encore plus objectivable après qu'une longue tradition d'enquêtes historiques et sociologiques ${ }^{20}$ lui eut permis d'apparaître comme un objet on ne peut plus légitime.

L'incubation du vote dans des limites définies à l'ombre des clochers n'attendit pas toutefois les appels répétés par certains, à compter des années 1980, à «communaliser» l'histoire, et l'histoire rurale en particulier ${ }^{21}$, pour exister sous la plume de certains spécialistes. Philippe Veitl rappelle ainsi dans ses «Lectures du Tableau politique d'André Siegfried " que si le "père fondateur "22 de la sociologie électorale ne modélisa en rien la dimension communale, «la valeur en soi de la dimension territoriale et la perception du local comme totalité suffisante compos[èr]ent un système explicatif dont il convient de trouver la logique d'articulation, en dépit des évidentes fautes de raisonnement qui le rendent illogique ${ }^{23}$. En résumant, au prix d'un certain nombre de raccourcis, l'on pourra dire que l'élection au village fut d'abord envisagée

18. Cf. l'article documenté de Jean-Louis Briquet et Frédéric Sawicki, «L'analyse localisée du politique. Lieux de recherche ou recherche de lieux?", Politix, n 7, 1989, p. 6-16; Philippe Secondy, La droite "extrême" dans l'Hérault (1890-1944). Sociologie historique d'une configuration politique, Thèse de science politique sous la direction de Paul Alliès, Université de Montpellier 1, 2001, volume 1, fo 29-44.

19. Maurice Agulhon, La République au village. Les populations du Var de la Révolution à la Deuxième République, Paris, Plon, 1970. Dans sa mise au point, "La République au village" : quoi de neuf?", Provence historique, tome 48, octobre-décembre 1998, p. 423-433, Maurice Agulhon rappelait combien la fortune de l'expression "au village» permit d'accommoder des travaux extrêmement différents pour devenir quasiment une catégorie en soi. $C f$. «La politique au village», titre d'une petite partie à l'intérieur de la contribution synthétique de Jean-Luc Pinol, "L'héritage d'une tradition politique ", in Yves Lequin [dir.] Histoire des Français, XIXé-XXe siècles, tome 3 : Les citoyens et la démocratie, Paris, Armand Colin, 1984, p. 9-169, p. 82-84; Yves Déloye, «L'élection au village. Le geste électoral à l'occasion des scrutins cantonaux et régionaux de mars 1992", Revue française de science politique, volume $43, \mathrm{n}^{\circ} 1$, février 1993, p. 83-106 (repris dans l'ouvrage d'Yves Déloye et Olivier Ihl, L'acte de vote, Paris, Presses de la Fondation Nationale des Sciences Politiques, 2008); du même auteur, "Le cléricalisme au village», cinquième chapitre inclus dans Les voix de Dieu. Pour une autre histoire du suffrage électoral: le clergé catholique et le vote, XIX'e-XXe siècle, Paris, Fayard, 2006, p. 179-216; Fabien Conord, "La vie politique au village", quatrième chapitre de Rendez-vous manqués. La gauche non communiste et la modernisation des campagnes françaises, Bordeaux, Presses universitaires de Bordeaux, 2010, p. 123-173.

20. Bertrand Müller, Lucien Febvre, lecteur et critique, Paris, Albin Michel, 2003, p. 252-255 en particulier.

21. Jean-Luc Mayaud, «Pour une communalisation de l'histoire rurale», in La politisation des campagnes au XIXe siècle. France, Italie, Espagne, Portugal. Actes du Colloque international organisé par l'École française de Rome en collaboration avec l'École normale supérieure (Paris), l'Universitat de Girona et l'Università degli studi della Tuscia-Viterbo, Rome, 20-22 février 1997, Rome, École française de Rome, 2000, p. 153-167.

22. Cf. Loïc Blondiaux et Philippe Veitl, «La carrière symbolique d'un père fondateur. André Siegfried et la science politique française après 1945 ", Genèses, n 37, décembre 1999, p. 4-26.

23. Philippe Veitl, «Lectures du Tableau politique d'André Siegfried», Politix, n² 29, 1995, p. $103-$ 122, p. 116. 
à travers la seule ratification - escomptée comme telle - des clivages idéologiques selon les lignes de démarcation qu'ils dictaient au niveau national. Un point de vue qui, en s'intéressant à la compénétration des dynamiques endogènes et exogènes, risquait d'étanchéifier toujours un peu plus le local d'un côté et le national de l'autre. Dans le sillage d'un Daniel Halévy qui écrivit que les républicains ayant "porté la République dans le village [...] dès lors, qui voudra[it] comprendre la politique du pays, c'est au village qu'il lui faudra[it] aller ${ }^{24}$, d'un Roger Thabault qui exemplifia la républicanisation de Mazières-en-Gâtine ${ }^{25}$, les historiens, tout comme les promoteurs de la géographie électorale de l'après-guerre, traquèrent presque exclusivement dans l'analyse localisée du politique une réfraction de l'opposition entre rouges et blancs, républicains et antirépublicains, gauche et droite et/ou une compréhension des mécanismes de production et de conquête du pouvoir. Paru en 1958 à la suite d'une table ronde qui s'était tenue deux ans plus tôt, l'ouvrage collectif, Les paysans et la politique dans la France contemporaine, codirigé par Jacques Fauvet et Henri Mendras, faisait la part belle à une analyse du vote appliquée à un cadre monographique. L'exercice canonique n'empêcha pas certains auteurs de rompre avec la traque des éléments prouvant l'existence d'une tradition de droite ou de gauche et de s'intéresser davantage aux substrats sociaux et culturels qui impliquaient tel comportement et tel type de mobilisation. La contribution de Lucien Gachon sur l'arrondissement d'Ambert, dont la dernière partie était dévolue à la formation du «comportement politique", s'ouvrait sur un long paragraphe qui abordait les fractures entre les rouges et les blancs en mêlant souvenirs personnels et chronique des consultations depuis la naissance de la Troisième République. Pour la première fois, à notre connaissance, la réification scientifique de la bipartition sous cet aspect bicolore, dont on voudra bien supposer qu'elle alimenta ultérieurement certaines lignes du Que sais-je? de Mendrass ${ }^{26}$, se fit en des termes que la plupart des auteurs qui s'intéressèrent aux élections ne démentirent pas ultérieurement : «Les deux courants : rouge et blanc, brassent la société. C'est de 1885 à 1914 qu'on peut dire le pays véritablement partagé, les deux familles électorales véritablement définies. La politique a ses deux pôles comme a les siens le globe terrestre en rotation. Bipolaire, la politique est à la fois passion et jeu. Passionnelle, elle a ses fanatiques qui, littéralement, voient tout blanc ou voient tout rouge $\aleph^{27}$. À bien des égards, la lecture - inspirée des thèses de Paul Bois sur l'événement révolutionnaire matriciel - que proposa

24. Daniel Halévy, La fin des notables, tome 2 : La République des Ducs, Paris, Grasset, 1937, p. 369.

25. Roger Thabault, Mon village : ses hommes, ses routes, son école, 1848-1914, Paris, Presses de la

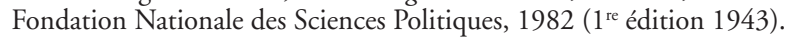

26. Henri Mendras nota : "Nos villages, nous l'avons dit, se divisent presque toujours en deux clans : les rouges et les blancs, les républicains et les réactionnaires, les partisans de l'instituteur et ceux du curé», Sociologie de la campagne française, Paris, Presses universitaires de France, "Que sais-je?», 1959 , p. 113.

27. Lucien Gachon, «L'arrondissement d'Ambert», in Jacques Fauvet et Henri Mendras [dir.], Les paysans et la politique dans la France contemporaine, Paris, Armand Colin, 1958, p. 389-429, p. 411. 
André Burguière, dans ses Bretons de Plozévetet ${ }^{28}$, de l'entreprise partisane d'une dynastie de notables radicaux qui, pour occuper le pouvoir et s'y maintenir pendant trois générations, surent capitaliser les ressources symboliques d'une partition socio-économique et culturelle pensée par les habitants de la commune bigoudène eux-mêmes à travers la double qualification rouges/ blancs, peut être considérée comme un archétype fameux de ces analyses qui fixèrent, une bonne fois pour toutes, l'opinion dans le village... Une opinion dont il s'agissait, dès lors, de scruter les évolutions (en termes de transferts de voix, d'alignements partisans, etc. $)^{29}$.

Si l'élection au village demeure toujours liée, dans de très nombreuses études historiennes, à cette dimension analytique de la mise en valeur d'une opinion $^{30}$, on notera qu'elle a servi, surtout depuis les années 1980, de toile de fond à la validation d'un certain nombre de paradigmes. Le «fait communautaire» fut vraisemblablement celui qui donna matière aux plus amples débats et c'est celui qui, faute de place pour d'autres développements, retiendra notre attention ${ }^{31}$. Sa (re) découverte ${ }^{32}$ a incontestablement bousculé une histoire du suffrage qui, en épousant implicitement le principe selon lequel tous les hommes étaient égaux en voix et en omettant, ce faisant, les réalités

28. André Burguière, Bretons de Plozévet, Paris, Flammarion, 1977 (1 $1^{\text {re }}$ édition 1975). Pour une lecture généalogique de l'intrusion puis de l'exhaussement du politique dans les ouvrages d'Edgar Morin (Commune en France. La métamorphose de Plozévet, Paris, Fayard, 1967) et d'André Burguière, nous nous permettons de renvoyer à notre contribution, " "Plozévet" : le politique comme "évidence" "?", in Bernard Paillard, Jean-François Simon et Laurent Le Gall [dir.], En France rurale. Les enquêtes interdisciplinaires depuis les années 1960, Rennes, Presses universitaires de Rennes, 2010, p. 227-258.

29. L'on soulignera que La République au village ne fit de l'élection au village ni un préalable ni un attribut du système interprétatif que Maurice Agulhon proposa dans le cadre de la coulée politisante; l'on constatera, en revanche, que les études de cas - le village unanime de Baudinard ou le village divisé de Cannet-du-Luc, par exemple - ne cessèrent d'utiliser le fait électoral comme un indice (parmi d'autres) d'un processus de politisation qui procéda en particulier, dans son Var, d'un patronage démocratique et d'une sociabilité par implication. Par ailleurs, on notera qu'au même moment, celui qui avait "contraint" Maurice Agulhon à travailler sur la première moitié du XIX siècle fit abondamment usage des élections dans ce qu'elles devaient dire des évolutions de l'opinion; $c f$. Émilien Constant, Le département du Var sous le Second Empire et au début de la III République, Les Mées, Association 1851 pour la mémoire des Résistances républicaines, 2009, volume 2.

30. Cf. la thèse de Christian Estève (À l'ombre du pouvoir. Le Cantal du milieu du XIXé siècle à 1914, Clermont-Ferrand, Presses universitaires Blaise-Pascal, 2002) où l'on suit, cartes à l'appui, l'évolution "politique» des communes depuis la couverture bonapartiste unanimiste du Second Empire jusqu’à la division entre un Cantal républicain et un Cantal conservateur dans les années 1870-1880.

31. La dynamique communautaire fut incontestablement la «star» du colloque de Rome dont nous avons déjà signalé les actes; $c f$., par exemple, la contribution de Jean-Pierre Jessenne, «Synergie nationale et dynamique communautaire dans l'évolution politique rurale par-delà la Révolution française (vers 1780-vers 1830)", in La politisation des campagnes au XIXe siècle. France, Italie, Espagne, Portugal..., op. cit., p. $57-79$.

32. Cf. Jean-Pierre Jessenne, Pouvoir au village et révolution. Artois, 1760-1848, Lille, Presses universitaires de Lille, 1987; Christian Thibon, Pays de Sault. Les Pyrénées audoises au XIXe siècle : les villages et l'État, Paris, Éditions du CNRS, 1988; Patrice Gueniffey, Le nombre et la raison. La Révolution française et les élections, Paris, Éditions de l'École des Hautes Études en Sciences Sociales, 1993. L’on soulignera que l'imposante thèse de Georges Fournier (Démocratie et vie municipale en Languedoc du milieu du XVIII au début du XIXe siècle, Toulouse, Association Les Amis des Archives de la Haute-Garonne, 1994, 2 tomes), dont l'écho demeure hélas affaibli, s’intéressa de près aux articulations entre démocratie électorale et dynamique communautaire. 
sociales d'un "cens caché »33, avait opportunément oublié que ces hommes étaient intégrés dans un tissu relationnel dont la collectivité villageoise, pour ce qui concernait les ruraux, était la forme la plus achevée ${ }^{34}$. Deux interprétations se disputent, en gros, les suffrages des uns ou des autres. Pour Alain Garrigou, par exemple, l'acte électoral étant déterminé par les conditions d'existence des agents au sein de leur communauté, le vote serait foncièrement communautaire sous la Seconde République puisqu'il viendrait consacrer le rôle des autorités, seules capables à la fois d'incarner le consensus et de mobiliser leur électorat ${ }^{35}$. Cet "unanimisme inégalitaire», fondé sur des rapports de domination, ne serait finalement qu'une ratification de logiques sociales à l'œuvre. Dans sa thèse sur les élections municipales sous la monarchie de Juillet, Christine Guionnet a proposé une tout autre approche de l'existence de ce vote ${ }^{36}$. Au cour de son analyse, la prégnance du «fait communautaire» dans la France de la première moitié du XIX ${ }^{\mathrm{e}}$ siècle aurait conditionné l'impossible présence du citoyen-électeur - parce qu'il était impensable... et donc impensé - dans les consultations municipales issues de la loi du 21 mars 1831. Condamné à n'exister qu'à travers le groupe étendu aux frontières de la collectivité d'appartenance et de domiciliation, l'individu capacitaire aurait été incapable d'envisager le champ politique local sous l'angle de l'altérité démocratique. En s'initiant sous la monarchie de Juillet "aux mécanismes de la vie politique démocratique libérale», les Français - et les habitants des campagnes les premiers - n'auraient pas pour autant fait l'«apprentissage des conceptions modernes de la politique ${ }^{37}$. L'unanimité des résultats chez les ruraux aurait donc beaucoup moins dépendu d'une incapacité à exprimer un vote politiquement signifiant, parce qu'il serait contraint, que d'un organicisme structurel qui empêchait qu'une individualisation politique puisse voir le jour dans des collectivités qui se pensaient par leur unicité et excluaient, ce faisant, celles et ceux qui paraissaient rompre le consensus unitaire. La résistance aux assauts de l'individualisme prôné par les défenseurs d'un projet démocratique mû par la volonté de débarrasser l'individu de ses gangues traditionnelles aurait ainsi trouvé une consécration dans les urnes. Par-delà les oppositions théoriques qui ressortissent à des sociologies du politique ayant quelquefois tendance à s'opposer artificiellement (l'existence d'un ethos collectif n'exclut nullement que l'intimisation des rapports

33. Daniel Gaxie, Le cens caché. Inégalités culturelles et ségrégation politique, Paris, Le Seuil, 1978.

34. Pour un résumé des débats qui s'appuie sur des travaux canoniques, on pourra se référer à l'ouvrage de Christian Le Bart, L'individualisation, Paris, Presses de la Fondation Nationale des Sciences Politiques, 2008, p. 113-116 et 133-136.

35. Alain Garrigou, Histoire sociale..., op. cit., p. 68 et p. 78-81.

36. Christine Guionnet, L'apprentissage de la politique moderne. Les élections municipales sous la monarchie de Juillet, Paris, L’Harmattan, 1997; "Un vote résigné et sans signification politique? Comportements électoraux paysans dans la première moitié du XIX siècle», Politix, n 37, 1997, p. 137-154.

37. Christine Guionnet, «Élections et apprentissage de la politique. Les élections municipales sous la monarchie de Juillet ", Revue française de science politique, volume 46, n 4, août 1996, p. 555-579, p. 578. 
de domination ait pu déboucher sur son renforcement), la réification du vote communautaire aura eu pour mérite d'obliger à reconsidérer les relations entre les électeurs dans les campagnes et leurs élections. Et permis de souligner combien il pouvait être utile de savoir se détourner du sens commun...

\section{L'ÉLECTION ET LE VILLAGE : UN PRODUIT SCALAIRE}

Donner des gages en faisant assaut de références parce que l'on prend pour terrain d'observation une commune participe indéniablement de l'ambiguïté qui entoure une monographie villageoise frappée progressivement d'obsolescence au fur et à mesure que des chercheurs en sciences sociales ont montré combien elle relevait, au préalable, d'un artifice fondé sur des prédispositions à accepter une ligne de partage claire entre ville et campagne, mondes urbains et mondes ruraux... Une ligne de partage dont la typification reposait aussi sur d'autres schèmes d'interprétation (l'opposition entre archaïsme et modernité en particulier $)^{38}$. Appliqué à la ruralité, le poids de la tradition monographique qui a pesé sur certaines pratiques disciplinaires - l'ethnologie de la France en a fait son mie ${ }^{39}$-, et dont nous avons pu constater qu'elle avait fréquemment enfermé l'étude du suffrage dans un recensement des forces en présence, seraitil suffisamment puissant pour oblitérer de nouveaux regards sur le village? Voire. Car, si l'on veut bien admettre que la commune n'est pas qu'une simple commodité (même si ce maillon administratif a créé les conditions archivistiques de son objectivation), l'on conviendra qu'elle peut devenir un observatoire de certaines situations à condition de la faire passer, par exemple, sous les fourches caudines de la démarche micro-historique. Et ceci pour au moins deux raisons. En premier lieu, parce que la commune était l'un des cadres privilégiés où s'effectuaient concrètement des relations sociales (même si plus personne n'est dupe du caractère forcément réducteur de cet enfermement territorial depuis que certains anthropologues - pensons ici au Marc Abélès des Jours tranquilles en 1989 - ont montré que l'espace politique local, considéré comme un entrelacs de réseaux, c'est-à-dire de "potentialités actualisables au gré des situations concrètes ${ }^{40}$, ne pouvait pas être borné par les seules limites administratives de la circonscription). En second lieu, parce que la genèse de la procédure électorale en tant qu’option généralisée de la délégation de la souveraineté sur l'ensemble du territoire national reste inséparable de la naissance

38. Cf. Patrick Champagne, "La fête au village», Actes de la recherche en sciences sociales, $\mathrm{n}^{\circ}$ 17-18, novembre 1977 , p. 73-84, p. 73.

39. Cf. Daniel Cefaï, L'enquête de terrain, Paris, La Découverte, 2003, p. 473-475.

40. Marc Abélès, Jours tranquilles en 89. Ethnologie politique d'un département français, Paris, Odile Jacob, 1989, p. 350. En se construisant comme une sphère spécifique dans la seconde moitié du XIX ${ }^{e}$ siècle, la sphère politique vit s'affermir le rôle de certains intermédiaires dont les fonctions électorales requéraient de transcender les limites communales; $c f$. François Miquet-Marty, «Les agents électoraux. La naissance d'un rôle politique dans la deuxième moitié du XIX ${ }^{\mathrm{e}}$ siècle", Politix, $\mathrm{n}^{\circ} 38$, 1997 , p. 47-62. 
des communes (même si le village de l'Ancien Régime fut le lieu d'une intense activité délibérative ainsi qu'un livre récent vient opportunément le rappeler ${ }^{41}$ ).

Démarche micro-historique, avons-nous écrit. Que nous ayons succombé à un effet de mode, cela va sans dire. On échappe difficilement à son époque ${ }^{42}$ et l'on se gardera bien de ne pas souligner combien la qualité de certains ouvrages qui se réclamèrent explicitement d'une «école» demeurée essentiellement italienne ne saurait disqualifier la richesse et la pertinence des autres approches ${ }^{43}$. Reste que la variation des échelles, dans ce qu'elle suppose d'un effort de prise en compte des moindres interactions à l'intérieur d'un segment d'une société et d'une attention particulière affectée aux effets de réel produits par les agents au moment même où ils laissaient des traces, nous a semblé pouvoir apporter un gain d'intelligibilité à la fabrication du fait électoral. Si l'on veut bien admettre que Le pouvoir au village $e^{44}$ nous aura suggéré de voir dans tout espace social un réservoir de possibilités multiples (mais non infinies) et définissables pour des individus et des groupes qui, en fonction de ce qu'ils en percevaient, opéraient des choix et s'adaptaient, et si l'on accepte de considérer l'opération électorale de la même façon (un réservoir de possibilités multiples...), l’on gagera qu’il $\mathrm{y}$ avait peut-être là matière à une adéquation entre un postulat de recherche et un objet d'histoire. Pour autant, dernier - et non pas ultime - terrain d'investigation de l'enquêteur soucieux de comprendre l'élaboration des procédures de la décision politique, la petite patrie ne serait-elle pas en passe de devenir la porte d'entrée dépoussiérée d'une discipline qui confondrait renouvellement paradigmatique et réductionnisme scalaire? L'on pourra toujours pointer les pièges afférents à cette démarche : utiliser la loupe grossissante pour habiller de nouveaux atours la bonne vieille monographie et faire émerger ainsi la version antépénultième d'un modèle sans qu'il contribue pour autant à un enrichissement de notre compréhension du social ${ }^{45}$; hypostasier un «exceptionnel normal ${ }^{46}$ au risque d'individualiser à outrance et, en individualisant à outrance, de

41. Antoine Follain, Le village sous l'Ancien Régime, Paris, Fayard, 2008, p. 245-279.

42. Cf. la contribution de Jacques Revel, "Microstoria», in Christian Delacroix, François Dosse, Patrick Garcia et Nicolas Offenstadt [dir.], Historiographies. Concepts et débats, Gallimard, 2010, tome I, p. 529-534.

43. Appelé à prononcer la conclusion du colloque de Rome, Maurice Agulhon souligna : "Études fines qui relèvent de la monographie sociologique et des analyses de mentalités collectives, à sources de base, à sources modestes. Plus proche cette fois de la microhistoire que de la "grande". Mais pourquoi pas? Ce n'est pas l'étendue géographique du champ qui fait forcément le mérite d'une œuvre, c'est l'intelligence qu'on lui applique", in La politisation des campagnes au XIXe siècle..., op. cit., p. 354.

44. Giovanni Levi, Le pouvoir au village. Histoire d'un exorciste dans le Piémont du XVII siècle, Paris, Gallimard, 1989 (1 $1^{\text {re }}$ édition 1985). Dans son introduction intitulée "L’histoire au ras du sol», Jacques Revel souligna que "le caractère intensif de la démarche micro-analytique a pour premier mérite de nous aider à mieux saisir l'enchevêtrement des logiques sociales, à mieux résister aussi à la tentation d'une réification des actions et des relations ainsi que des catégories qui nous permettent de les penser ", p. I-XXXIII, p. XIII.

45. Gérard Béaur, «Les catégories sociales à la campagne : repenser un instrument d'analyse», Annales de Bretagne et des Pays de l'Ouest, tome 106, n 1, 1999, p. 159-176, p. 172. Cf., aussi, le chapitre intitulé "De l'échelle en histoire» dans l'ouvrage de Bernard Lepetit, Carnet de croquis. Sur la connaissance historique, Paris, Albin Michel, 1999, p. 88-119, en particulier p. 100-101.

46. Edoardo Grendi, «Micro-analisi e storia sociale», Quaderni storici, n 35, 1977, p. 506-520, 
cautionner par avance la théorie de l'individualisation démocratique au cours du XIXe siècle.

Cette approche écologique du suffrage, c'est celle qui, sans que nous ne la nommions de la sorte $e^{47}$, aura servi en définitive dans le cadre d'une thèse consacrée à l'électeur en campagnes dans le Finistère sous la monarchie de Juillet et la Seconde République. En tablant sur une observation intensive du vote ${ }^{48}$, en incluant les mandants dans leur environnement quotidien ${ }^{49}$ pour éviter de les assigner à n'être que les figures génériques et fréquemment anonymes d'une citoyenneté en devenir (que l'historien se plairait à convoquer à sa table de travail au moment de prouver qu'ils furent des agents concourant à l'élaboration d'un ordre démocratique intégrateur et/ou des cohortes de votants plus ou moins passifs en attente de labellisation), nous aurons essayé de retrouver le sens que des individus donnèrent à l'acte électoral - saisir les électeurs sur le vif - dans un Finistère auquel les administrateurs de l'époque dénièrent toute volubilité démocratique.

On l'aura compris. Il ne s'agit pas de parer la micro-analyse appliquée à l'élection au village de toutes les vertus heuristiques mais d'en faire, à partir d'une étude localisée et des comparaisons qu'elle est susceptible d'induire, soit un cadre de validation ou d'invalidation d'hypothèses ou de théories en cours, soit un cadre d'interprétation des réalités sociologiques imperceptibles à une autre échelle.

\section{L'ÉlECTION AU VILlage : CHERCHER À PERCER "LES MYSTÈRES DU MINISTÈRE " 50 ?}

\section{Lectures en cours}

Première lecture : la mise en place d'une civilisation électorale et d'un ordre démocratique au quotidien. L'on ne reviendra pas ici sur un objet abondamment défriché et qui a été posé en termes de rationalisation de l'en-

p. 512; cf., à propos de l'utilisation de cet oxymoron, les remarques de Carlo Ginzburg, "Carlo Ginzburg, "L'historien et l'avocat du diable". Entretien avec Charles Illouz et Laurent Vidal», Genèses, n 53, décembre 2003, p. 113-138, p. 122-123.

47. Parenté méthodologique avec la démarche de Céline Braconnier et Jean-Yves Dormagen, La démocratie de l'abstention. Aux origines de la démobilisation électorale en milieu populaire, Paris, Gallimard, 2007. Voir aussi l'ouvrage de Céline Braconnier, Pour une autre sociologie du vote. Appréhender les électeurs dans leurs contextes : bilan et perspectives, Cergy-Pontoise, LEJEP, 2010.

48. Notre étude s'est appuyée, en particulier, sur le dépouillement exhaustif des scrutins généraux et départementaux des années 1848 et 1849 ( 43 cantons et 119 sections en décembre 1848), des élections municipales dans les 282 communes du Finistère en 1848 et lors des deux derniers renouvellements de la monarchie censitaire (1843 et 1846), et sur une microsociologie des comportements électoraux de centaines de suffragants domiciliés dans cinq communes. L'analyse des résultats des deux plébiscites de décembre 1851 et novembre 1852 et des rendez-vous municipaux de septembre 1852 a permis de fermer la boucle électorale.

49. D'où la volonté de faire feu de tout bois en croisant les sources et en accumulant les traces.

50. Pierre Bourdieu, "Le mystère du ministère. Des volontés particulières à la "volonté générale" ", Actes de la recherche en sciences sociales, $\mathrm{n}^{\circ} 140$, décembre 2001, p. 7-11. 
treprise électorale et de travail étatique de domestication des comportements devant le vote ${ }^{51}$. Le village ne sert alors que de déclinaison à ce que l'on sait par ailleurs des mécanismes d'organisation, d'imposition et de normalisation d'un marché politique fondé préférentiellement sur le suffrage ${ }^{52}$. Quelques approfondissements sont toutefois possibles. Nous en listerons deux. Le premier concerne la fabrication et l'utilisation des résultats des consultations. Incarnation d'une opinion le plus souvent postulée qu'objectivée, ainsi que nous l'avons rappelé, le chiffre électoral a été doté de vertus idéologiques avant même d'être étudié pour ce qu'il fut peut-être et surtout : un chiffre fabriqué, dépendant de mobilisations variables - la fatigue des votants, la distance à l'urne et l'obligation de voter par soumission n'expliquent pas tout, loin s'en faut - et de rapports de force intra et/ou intercommunaux dont le bureau de vote était le théâtre. L'examen des bulletins «douteux" par les scrutateurs et leur qualification, outre qu'ils pouvaient influer marginalement sur les résultats, furent bien davantage qu'une entreprise de vérification, comme en témoignent les micro-conflits qui se nouaient pendant les dépouillements. Il serait en effet fallacieux d'imaginer l'encadrement des consultations comme une simple mise en application de lois et de textes incarnant, à bien des égards, la rigueur d'un État omnipotent et omniscient. Grâce à la liberté qui fut laissée à des bureaux sommés d'apprécier la situation électorale, l'administration fit confiance à des agents locaux - mais pouvait-elle faire différemment, à moins de poster un de ses représentants dans chaque lieu de vote?... - et laissa inévitablement libre cours à des dérives qu'elle essaya, au mieux, de prévenir puis de contenir - le conseil de préfecture était là pour trancher les contentieux à la suite des opérations. Paradoxalement, l'incapacité de l'État à tout régir et à tout régler, et la marge d'appréciation dont disposaient mécaniquement les scrutateurs, contribuèrent à forger les conditions d'un débat autour de l'application de la norme démocratique. En déléguant une partie de ses droits régaliens, l'administration facilita la prise de conscience que la procédure électorale sanctionnait non seulement des choix politiques mais aussi l'implication de certains individus dans le propre devenir d'une nation de citoyens. En faisant des bureaux de vote les applicateurs d'une règle démocratique et ses possibles incubateurs, elle suggéra que l'astreinte à un code n'allait pas sans sa discussion par ceux qui s'en faisaient momentanément les porteurs. L'inachèvement involontaire de cette norme porta en lui, en quelque sorte, une appropriation possible des mécanismes

51. Dans une littérature abondante, on mentionnera, en sus des références précédemment citées, l'ouvrage d'Yves Déloye et Olivier Ihl, L'acte de vote..., op. cit., et deux articles d'Yves Pourcher, «Passions d'urne. Réflexions sur l'histoire des formes, des pratiques et des rituels de l'élection dans la France rurale», Politix, n 15, 1991, p. 48-52; "Tournée électorale», L’Homme, n 119, juillet-décembre 1991, p. 61-79.

52. La centralité du suffrage dans l'organisation de l'ordre démocratique imposa toute une gamme d'activités qui participèrent à sa pérennisation; $c f$. Paula Cossart, Le meeting politique. De la délibération à la manifestation (1868-1939), Rennes, Presses universitaires de Rennes, 2010, en particulier p. 115158. 
de la décision populaire qui facilita les conditions d'épanouissement d'une démocratie de proximité.

Le second approfondissement que nous suggérerons touche aux liens entre la construction d'un ordre démocratique et la construction d'un ordre étatique à travers la figure éminemment présente du citoyen protestataire. Prescriptrices d'un ordre démocratique lié à un encadrement technologique exigé par l'État, les consultations des commettants favorisèrent l'inculcation d'un système normatif dont les élections de 1848, après celles organisées sous la monarchie censitaire, amplifièrent et systématisèrent la mise en place. L'inflation de la verve contestataire et des incidents au moment du renouvellement des assemblées municipales atteste les craintes, les ambitions ou les attentes attisées par l'universalisation masculine du suffrage ( 42 communes furent touchées par 47 incidents en 1846; 66 communes le furent par 71 incidents en 1848; entre 1846 et 1848, 90 communes, soit près d'un tiers des 282 localités du Finistère, furent donc frappées par au moins une plainte qui dénonçait le déroulement du premier et/ou du second tour). Partie intégrante des scrutins, la protestation souligne combien la production d'une déviance électorale ${ }^{53}$ dépendit de l'omniprésence d'un gardien du temple. Garant des textes et de la loi, le citoyen protestataire, qui savait en général lire, écrire, et intercéder auprès des instances de contrôle, apparaît en effet, au moment où le suffrage demeurait pour beaucoup une nouveauté, comme une quintessence d'une acculturation démocratique en cours et, bien souvent, comme un individu soucieux d'utiliser la forme suprême de la délégation du pouvoir à des fins personnelles. Sa compétence politique, qui tranchait alors avec l'infinie diversité des comportements électoraux de ses contemporains, ne saurait faire oublier qu'il fut surtout l'aiguillon d'une surveillance politique individuelle légitimée au nom d'une morale de l'État (dans un univers où régnait un contrôle social fondé sur le jeu des regards). Alors même que les porte-parole de la collectivité villageoise, et les maires en particulier, ne cessaient d'accréditer, aux yeux des autorités extérieures, l'existence d'une communauté homogène, indivisible et farouchement attachée à un système de valeurs endogène, ce parangon de la vertu et/ou ce manipulateur hors pair levait un coin du voile sur l'arrière-plan des scrutins. Au risque de faire de la transparence démocratique le cheval de Troie d'une intrusion étatique en mesure de lézarder l'opacité dans laquelle étaient tenues certaines affaires villageoises.

53. "Compter n'est pas comprendre": énoncée au tout début de l'introduction de la thèse de science politique qu'a consacrée Nathalie Dompnier à la fraude électorale (La clef des urnes. La construction socio-historique de la déviance électorale en France depuis 1848, sous la direction d'Olivier Ihl, Institut d'études politiques de Grenoble, 2002, volume 1, fo 4), cette pétition de principe nous paraît un peu abrupte. Sans être un thuriféraire du dénombrement, nous rappellerons que la quantification des actes frauduleux par les diverses autorités en charge des consultations participa aussi à la production d'une norme électorale en fonction de laquelle chaque mandant était appelé à se positionner. 
Deuxième lecture : la lente invention de l'électeur moderne par apprentissage et incorporation des mécanismes du vote. Le village ne serait, ici aussi, qu'un réflecteur de ce que nous connaissons déjà, à moins de penser le suffrage tel un dispositif qui, de par son existence et son utilisation, générerait une certaine forme de politisation. Soit notre approche de ce terme éminemment ambigu ${ }^{54}$. Produit d'une histoire pluriséculaire, une "politique du peuple ${ }^{55}$ des campagnes, réductible à un faisceau d'idées, de sentiments et de notions partagés par la plupart de ses membres - antifiscalisme, autonomie communautaire, attachement à la petite patrie -, trouva à s'épanouir et à se recomposer à l'intérieur d'un ordre démocratique qui s'imposa avec le temps. La politisation ne saurait donc se réduire à la substitution d'un modèle à un autre ou à l'éradication de pratiques archaïques. Elle ressemble bien davantage à une métamorphose des attitudes et des comportements dans un champ politique en évolution ou, pour le dire autrement, à une zone de contact - ce qui suppose une réciprocité des influences - entre les nouveaux cadres de la démocratie et des expériences anciennes ${ }^{56}$. Nous postulerons alors que le suffrage en tant que procédure aura pu être un élément "politisateur» dans la France de la monarchie de Juillet et de la Seconde République pour une raison au moins : en devenant le principal mécanisme de masse de la décision collective, il contraignit tout agent qui pouvait bénéficier du droit de vote - et celles et ceux qui l'entouraient -, quel que soit son positionnement dans l'espace social, à se situer en fonction du cadre et des normes imposés. En élevant la citoyenneté électorale au premier rang des valeurs cardinales de la citoyenneté, le gouvernement républicain modifia - dans un sens démocratique - les règles d'un jeu politique pour mieux en valider la pertinence et l'effectivité. L'on put être contre le suffrage (universel), ne pas vouloir voter, ne pas savoir voter (par méconnaissance des règles). Pour autant, l'on put de plus en plus difficilement se soustraire à ce qu'il prescrivit, induisit et imposa ${ }^{57}$. Si l'on veut bien admettre cette hypothèse, l'on pourra essayer de sérier des niveaux de politisation par le vote à condition de la définir, lato sensu, comme la somme des rapports qu'entretinrent individus et groupes d'individus avec une procédure démocratique considérée sous son double aspect de fabrication du citoyen-électeur et de détermination de l'opinion. De façon minimaliste - et un peu simpliste,

54. Un état des lieux stimulant de ce que la politisation peut vouloir dire dans l'article de Myriam Aït-Aoudia, Mounia Bennani-Chraibi et Jean-Gabriel Contamin, "Contribution à une histoire sociale de la conception lagroyenne de la politisation", Critique internationale, $\mathrm{n}^{\circ} 48,2010$, p. 207-220.

55. Roger Dupuy, La politique du peuple, XVIII $-X X X^{e}$ siècle. Racines, permanences et ambiguïtés du populisme, Paris, Albin Michel, 2002.

56. Nous reprenons, ici, la formulation que nous avons donnée dans notre contribution, «Des processus de politisation dans les campagnes françaises (1830-1914). Esquisse pour un état des lieux", in Jean-Claude Caron et Frédéric Chauvaud [dir.], Les campagnes dans les sociétés européennes. France, Allemagne, Espagne, Italie (1830-1930), Rennes, Presses universitaires de Rennes, 2005, p. 103-139, p. $107-108$.

57. Cf. Frederick George Bailey, Les règles du jeu politique. Etude anthropologique, Paris, Presses universitaires de France, 1971 (1 $1^{\text {re }}$ édition 1969), p. 13-25. 
certainement -, cette distinction entre le rôle et la valeur du suffrage renverra à plusieurs seuils de politisation sur une échelle qui fait de l'utilisation du suffrage-procédure son premier niveau (l'intégration individuelle à un ordre démocratique n'étant pas forcément corrélée à un maniement du vote pour faire admettre son positionnement à l'intérieur de l'espace politique) et de l'utilisation du suffrage-opinion son dernier degré - la question de l'abstention supposant, en contrepoint, d'établir si - et quand - elle fut un révélateur d'une indifférence ou, au contraire, d'une distinction voire d'une opposition (à teneur politisante) $)^{58}$.

Une fois ces préalables posés, nous sommes parvenu à plusieurs conclusions à partir, entre autres éléments, d'une analyse longitudinale et microsociologique de 1074 mandants dispersés dans cinq communes du Finistère ${ }^{59}$, et dont nous avons pu retracer les parcours électoraux. S'est imposée une évidence : le commettant de 1848 se laisse difficilement enfermer dans des paramètres (stratigraphies sociales, richesse/pauvreté, etc.) forgés par l'historien pour essayer de le prendre dans ses filets - le degré d'alphabétisation ou l'inclusion dans le réseau familial ne semblent guère entrer en ligne de compte. L'électeur moyen reste introuvable; le votant erratique domina et la volatilité des mobilisations fut reine. Les situations furent à ce point variées que les pratiques des mandants échappent à toute typologie. À Nizon, par exemple, un seul homme ne déposa pas son bulletin entre 1832 et 1848 : le curé. Deux constatations se seront toutefois progressivement imposées. Premièrement, la familiarisation avec la procédure démocratique dépendit surtout des antécédents électoraux de chaque individu. On s'abstint d'autant moins que l'on s'était présenté à plusieurs reprises devant l'urne. En 1848, les anciens censitaires, qui étaient aussi les plus riches de la commune et qui avaient pour certains appris à voter depuis près de vingt ans, partaient avec une sacrée longueur d'avance sur les tout nouveaux inscrits. L'étiage exceptionnel de leur participation lors du renouvellement des conseils municipaux de juillet ne fut donc que la suite logique d'un mouvement de fond initié par la loi du 21 mars 1831 et le reflet d'un capital démocratique qu'ils avaient accumulé et qu'ils entendaient faire fructifier. Deuxièmement - et c'est un corollaire -, il y eut un véritable remuement électoral en 1848 qui vint briser l'équilibre censitaire qui s'était peu à peu construit au cours des quinze années précédentes. En créant de la nouveauté, la dilatation du droit de vote avait ouvert sur l'inconnu. Aussi la mobilisation des anciens privilégiés du

58. Une comparaison qui tend à prouver que notre hypothèse de départ est tout à fait réfutable... Sylvain Milbach écrit : «Il semble donc que l'élection en tant que telle, c'est-à-dire en tant que pratique, n'est pas en Savoie au cœur du processus de politisation ou d'apprentissage de la politique.», L'éveil politique de la Savoie. Conflits ordinaires et rivalités nouvelles (1848-1853), Rennes, Presses universitaires de Rennes, 2008, p. 97.

59. L'Hôpital-Camfrout (579 habitants en 1846, 154 électeurs en 1848), Le Folgoët (905 habitants en 1846, 212 électeurs en 1848), Le Ponthou (418 habitants en 1846, 97 électeurs en 1848), Mahalon (1381 habitants en 1846, 306 électeurs en 1848), Nizon (1 292 habitants en 1846, 305 électeurs en 1848). 
suffrage fut-elle à la mesure de la peur qu'ils eurent de ne plus peser suffisamment sur les résultats. Une réponse par le nombre et l'habitude de la fréquentation des urnes à l'égalisation formelle d'une condition démocratique qui avait été naguère un critère de distinction et de différenciation.

Les interrogations concernant la maturation de la figure du citoyen-électeur permettent, au surplus, de réexaminer les liens entre holisme et individualisme. De la moisson de chiffres consécutive à une analyse approfondie des résultats des consultations nationales qui se tinrent dans le Finistère entre le 23 avril 1848 et le 13 mai 1849, il ressort quelques observations qui brouillent, de prime abord, un peu plus les pistes. Certains dépouillements accréditent incontestablement l'existence d'un vote unanimiste : dans le canton de Lannilis, lors du scrutin présidentiel, les trois sections votèrent presque comme un seul homme pour un seul homme puisque Cavaignac l'emporta avec plus de $95 \%$ des suffrages. D'autres, en revanche, minorent cette tendance : 33 communes devinrent des sections en décembre $1848 ; 16$ d'entre elles virent leurs électeurs se prononcer à plus de $80 \%$ pour l'un des deux favoris; dans les 17 autres, les résultats furent beaucoup plus contrastés pour des raisons qui nous échappent sauf lorsqu'un scrutin à enjeu national servit quelquefois de réplique aux turbulences qui avaient pris forme au moment des élections municipales. Penchons-nous, à rebours, sur le scrutin d'avril. Les Finistériens eurent à écrire, faire écrire ou à placer un bulletin imprimé qui devait comporter quinze noms. Des listes s'affrontèrent. Elles n'exclurent pas toutefois une hétérogénéité des conditions d'accès à la candidature ainsi que l'attestent les procès-verbaux cantonaux qui mentionnèrent une pléthore de soupirants à la députation (avec une moyenne de 102 noms par feuille de dépouillement). Les premières élections au suffrage universel débouchèrent sur un double phénomène : une offre politique qui s'élargit considérablement; la capacité qu'eurent certains hommes de se démarquer des consignes générales des grands comités départementaux pour tenter leur chance. Ce ne sont là que quelques exemples et l'on pourrait les multiplier à l'envi. Aussi les conclusions auxquelles nous sommes parvenu se résumentelles en quelques points. Premièrement, l'empire du collectif pesa incontestablement, lorsqu'il fallait se déplacer au chef-lieu de canton, sur les scrutins généraux, du fait même de l'interaction entre les modalités du vote - chaque commune était appelée à s'exprimer à une heure précise - et le sentiment, présent chez la plupart des participants, d'aller défendre en dehors de leur circonscription une identité façonnée par le groupe et le territoire d'appartenance. Deuxièmement, cette pratique holiste n'évacua pas pour autant l'individu de la scène politique. L'expression individuelle d'un choix, au nom d'une opinion ou d'un désir de se démarquer d'une collectivité, ne fut en rien exceptionnelle même si elle demeura minoritaire : les "candidats à une ou deux voix» furent monnaie courante avant le rétrécissement de l'offre électorale au fil de l'année. 
Par ailleurs, la question de la constitution des bastions politiques peut nous aider à y voir un peu plus clair. Il nous semble, en effet, que la déconstruction de la mobilisation électorale ne suppose pas, symétriquement, de condamner à l'échec toute tentative de labellisation idéologique quand bien même une sociologie critique du politique nous a désappris à penser l'élection comme la seule production d'une opinion qui ne cesserait de sédimenter avec le temps. En agrégeant les données des scrutins nationaux de 1848 et 1849, nous avons constaté que la couleur du vote fut confirmée à chaque reprise dans 14 des 43 cantons et qu'elle fut le fruit d'un résultat quasiment unanime en faveur des candidats clérico-légitimistes dans certaines circonscriptions. Dans les cinq cantons léonards (Lannilis, Lesneven, Ouessant, Plabennec, Ploudalmézeau) et dans celui d'Arzano, la réactivation des modalités du vote (unanimité idéologique, mobilisation massive) participa à la création d'un passé électoral qui présida, de façon plus prégnante qu'ailleurs, à l'«institutionnalisation " d'un rapport univoque entre des communautés de suffragants et la procédure démocratique. On fera l'hypothèse que, dans ce cas, la répétition des scrutins contribua à ce que la communauté se pense comme un bloc homogène - une forme exceptionnelle de la communauté politique - dont l'homogénéité se nourrissait précisément de la réplique des scrutins. Une configuration qui ne réservait d'autre alternative à l'individu réfractaire que de s'exclure du groupe et/ou d'en être exclu. En revanche, une individualisation par l'élection parut se dessiner d'autant plus aisément que les suffragants appartenaient à des circonscriptions qui ne devinrent pas des bastions clérico-légitimistes. L'étude des comportements politiques dans 31 communes qui étaient aussi des chefs-lieux de section en décembre 1848 et en mai 1849 nous aura incité à faire l'hypothèse suivante : alors que dans les localités à tendance clérico-légitimiste, le vote en faveur des candidats fut quasiment unanime, dans les localités à tendance républicaine, les résultats furent beaucoup plus contrastés (basculements entre les scrutins, friabilité des mobilisations, inconstances des positionnements devinrent le lot commun des élections). L'on ne peut alors s'empêcher de penser - mais le corrélat est peut-être audacieux et il supposerait d'être vérifié ailleurs - que les communes à tendance républicaine furent non seulement le théâtre d'une hétérogénéité politique mais qu'elles participèrent à la dilatation de l'espace public. Si l'opposant avait tout de la figure de l'ennemi, il n'en devenait pas moins un élément permanent de l'espace électoral... détesté sans doute, mais pensé dans son altérité tout de même. L'espace politique local pouvait alors se construire moins dans l'unanimité que dans la diversité. Bref, plus démocratiquement ${ }^{60}$.

60. Pour une analyse très fine de l'existence du vote communautaire, on se référera à l'étude d'Adeline Connan, Le vote "communautaire» et son dépérissement dans le Morbihan sous la Troisième République. Étude de statistiques électorales dans l'arrondissement de Ploërmel (1876-1914), mémoire de master 1 sous la direction de François Ploux, Université de Bretagne-Sud, 2008. À la suite d'une analyse sta- 
Troisième lecture : considéré pour sa teneur politisante, le suffrage peut aider à affiner certaines analyses canoniques qui se rapportent aux voies d'accès au pouvoir local et à sa distribution. Politisation par implication, la politisation par le bulletin commanda en effet des positionnements spécifiques que la conflictualité électorale ${ }^{61}$, qui déboucha dans quelques cas sur des crises perlées, laisse appréhender. L'année 1848 fut ainsi marquée dans le Finistère, comme un peu partout en France, par de virulents conflits dont le vote fut à la fois le puissant détonateur et le symptôme de tensions souterraines. Pour un lecteur de la série $\mathrm{BB}^{18}$ des Archives nationales, l'affaire qui tint en haleine la commune d'Hanvec (un peu plus de 3000 habitants) sous la Seconde République se résume prosaïquement à une querelle entre un curé et un maire dont l'écume parvint jusqu'aux bureaux du ministre de l'Intérieur (rien d'exceptionnel à cela puisque cette série regorge de tels conflits). Pour un lecteur des sources conservées aux Archives départementales et communales, les fils de l'histoire apparaissent beaucoup plus difficiles à retisser. Le conflit mit aux prises Pierre Kerloch, un ecclésiastique sûr de ses droits et de ses prérogatives, et Olivier Salaün, un notaire véreux qui avait été mis sur la touche par l'administration au début des années 1840 - alors qu'il occupait les fonctions de maire - après qu'il eut ouvert un tripot et plumé parmi les plus riches paysans de la localité. 1848 fut pour Salaün une aubaine, un coup du sort inespéré. Redevenu le primus inter pares à la faveur de la consultation de juillet et après avoir exercé des pressions sur sa clientèle rurale, il fit de sa mairie la caisse de résonance d'un anticléricalisme d'autant plus outrancier que son adversaire n'entendit pas se laisser faire. La réciprocité de la haine ordinaire trouva à s'épanouir dans des histoires de bancs d'église ou de quêtes interdites. Jusqu'à son éviction en 1851, tout devint prétexte à l'envenimation des relations, à tel point que le notaire n'hésita pas à jouer le préfet contre le procureur général pour mieux résister aux pressions des autorités extérieures dont il fut de plus en plus l'objet. Au-delà des péripéties qui émaillèrent un conflit devenu endémique, l'analyse de la commune en crise que fut le Hanvec quarante-huitard nous aura permis de tirer quelques conclusions. Premièrement, la République fut un cadre d'exercice d'une guérilla qui passa par les urnes sans qu'elle devienne un enjeu idéologique dont l'un des deux camps aurait pu s'emparer pour fourbir ses armes et capitaliser des dividendes électoraux sur un partage politique savamment utilisé. Deuxièmement, le diptyque cléricalisme/anticléricalisme trouva d'autant plus facilement à s'épanouir qu'il se lova à l'intérieur de deux institutions locales,

tistique approfondie, Adeline Connan souligne combien les résultats électoraux unanimistes qui firent du Ploërmelais le bastion politique du duc de Rohan dépendirent de la mobilisation continuelle des mandants entreprise par les autorités traditionnelles (et le clergé en premier lieu).

61. Pour un contrepoint contemporain, on se référera à l'article de Jean-Yves Nevers, «Entre consensus et conflits. La configuration des compétitions aux élections municipales dans les communes rurales ", Revue française de sociologie, volume 33, n 3, 1992, p. 391-416. 
le conseil municipal, d'un côté, et le conseil de la fabrique, de l'autre, dont la légitimité ne cessa de croître au fur et à mesure qu'elles devinrent des forteresses à prendre mais aussi à défendre (en dépit de leur animosité à l'endroit du notaire, les préfets utilisèrent toutes les ressources à leur disposition pour protéger les attributions du conseil municipal au nom de la séparation des pouvoirs entre le municipal et le paroissial). Troisièmement, Olivier Salaün put exister en l'espèce parce que la collectivité hanvecoise lui permit d'exister ainsi. En d'autres termes, si ce conflit ne fut ni un conflit de classes, ni un conflit territorial, alors même que des forces centrifuges étaient à l'œuvre à l'intérieur de cette commune éclatée (et pour cause! la société des montagnes d'Arrée avait peu de chose en commun avec la société littorale qui, dans le sud de la circonscription, regardait vers Brest et Le Faou), il fut le produit de la rencontre entre un homme et un corps social travaillé en partie par la laïcisation et le détachement religieux.

En sus de ces trois remarques qui sont plus descriptives qu'analytiques, nous ferons deux autres constatations. La première porte sur les ressorts conflictuels d'une politisation qui, dépassant le niveau de l'apprentissage électoral, tendrait vers une insertion de certains de ses agents dans un espace politique aux dimensions et aux enjeux nationaux. Si l'opposition frontale put permettre à des hommes, mais aussi à des femmes (l'épouse de Salaün fut en première ligne dans la lutte contre le curé), de napper leur combat d'une dimension proprement idéologique sans qu'il soit facile d'identifier à distance ce qui, dans cette adhésion par bribes (celles qui ont été archivées), releva d'un artifice ou d'une imprégnation, nous aurons pu noter que le prurit anticlérical, qui fut très majoritairement - pour ne pas dire exclusivement - à la base de la bipolarisation électorale dans le Finistère, ne déboucha pas toujours sur la fabrication ou l'affermissement d'une opinion. Les passerelles entre anticléricalisme et républicanisme dans l'intégration de certains suffragants à un espace politique qui n'était pas seulement celui des joutes locales furent ainsi bien plus ténues qu'on ne le suggère fréquemment. La seconde remarque concerne les rapports entre le conflit électoral et le bouleversement possible de la sphère municipale. Il y eut bien dans le Finistère une révolution communale... sauf qu'elle le fut en trompe-l'œil. Si plus de $30 \%$ des maires ne furent pas reconduits dans leurs fonctions après les scrutins de l'été 1848 , plus de $80 \%$ des conseillers municipaux furent quant à eux réélus. Le conflit électoral quarante-huitard, qui vit généralement s'affronter des édiles élus sous la monarchie de Juillet, prit donc presque exclusivement naissance à l'intérieur d'une ploutocratie municipale que le régime louisphilippard avait renforcée du fait même de son onction par le vote. L'utilisation du suffrage universel ne fit alors que conforter une oligarchie locale qui put se construire comme une classe municipale de plus en plus étanche pour au moins deux raisons : elle venait non seulement de recevoir l'adhésion d'un corps de citoyens qui s'était démocratisé, mais elle avait aussi su résister 
aux coups de boutoir nés des appétits que ledit suffrage avait aiguisés. En verrouillant la conquête du pouvoir - ce qui signifiait avant tout qu'il n'y avait pas d'autre alternative possible -, une élite, qui pouvait se quereller et se diviser temporairement, incarnait, au-delà des péripéties nationales, la continuité de la communauté et les impossibles changements (qui étaient aussi d'impensables changements). D'une certaine manière, l'ascension du municipal tout au long du XIX $\mathrm{X}^{\mathrm{e}}$ siècle fut rendue en partie possible parce que l'ébranlement électoral de 1848 ne mit qu'exceptionnellement à mal une architecture oligarchique construite de longue date. Si la réintroduction du suffrage universel conditionna, chez certains acteurs, une aptitude à imaginer une recomposition du pouvoir local (l'entrée en lice de nombreux notables contribua à la formation d'un proto-marché politique et entraîna, ce faisant, un lien de dépendance non univoque entre les élites traditionnelles et leurs suffragants), elle consacra en définitive une captation rapide des instances communales par une élite censitaire dont l'idéologisation à plus ou moins long terme pourrait être une des clés de l'acculturation d'une population à des enjeux nationaux. Une version finistérienne de la classique «descente de la politique vers les masses " - sans patronage démocratique ni réseaux de sociabilité ${ }^{2}$ - dont l'étude sur une longue durée - jusqu'aux premières décennies de la Troisième République - permettrait de vérifier la pertinence.

\section{Deux pistes}

\section{- La territorialisation de l'élection}

Patente dans le cadre des élections nationales ou départementales qui furent aussi des moments d'effervescence locale, la variable territoriale entre en ligne de compte dès lors que l'on veut essayer de comprendre les ressorts de la mobilisation au moment des élections qui se déroulaient au chef-lieu de canton. Non seulement les rapports de force intercommunaux trouvaient à s'exprimer dans l'urne, mais ils pouvaient conditionner aussi ce qui allait sortir de l'urne. Soit le canton de Carhaix lors du scrutin du 10 décembre 1848. Bonaparte y obtint un peu plus de $51 \%$ des suffrages. Si l'on vota à $78 \%$ dans la section de Carhaix pour le neveu de l'Empereur, on se prononça respectivement à $64 \%$ et à $82 \%$ dans les sections de Saint-Hernin et Poullaouen pour son adversaire, Cavaignac. La plupart des communes de la circonscription carhaisienne récusèrent donc le candidat du "parti de l'ordre». Rien que de très normal finalement : la moyenne cantonale masque la pluralité des dépouillements sectionnaires. Si l'on passe maintenant à une tentative d'explication des résultats, l'on sera inévitablement tenté de faire appel à certains paramètres économiques et sociaux ou au rôle de certaines autorités de

62. Cf. Laurent Le Gall, «La politisation sans la "sociabilité" ? Une piste finistérienne (première moitié du XIX siècle)", in Annie Antoine et Julian Mischi [dir.], Sociabilité et politique en milieu rural. Actes du colloque organisé à l'université Rennes 2 les 6,7 et 8 juin 2005, Rennes, Presses universitaires de Rennes, 2008, p. 263-274. 
tutelle (la gendarmerie de Carhaix rappela dans un rapport adressé au préfet que les deux compagnies d'artillerie de marine stationnées au chef-lieu de canton avaient pesé lourdement dans la poussée en faveur de Bonaparte). Des détails plaident toutefois en faveur de la prise en compte d'une autre variable, la variable territoriale. L'hypothèse est la suivante : voter à plus de $80 \%$ pour Cavaignac dans la section de Poullaouen qui formait en même temps une seule et même commune, n'était-ce pas une manière pour ses habitants de se démarquer d'un chef-lieu dont on savait pertinemment (la rumeur était là pour cela) que ses mandants voteraient massivement en faveur de Bonaparte? La disqualification de certains bulletins par les membres des bureaux électoraux atteste que la manipulation des chiffres répondit bel et bien à des antagonismes intercommunaux. Si, dans la section de Carhaix, les scrutateurs rejetèrent une vingtaine de bulletins Cavaignac pour des incompatibilités de forme, à Poullaouen, ce furent près de 120 billets «Bonaparte» qui furent disqualifiés pour leur prétendue illisibilité.

Si l'on se place maintenant à l'échelle de la localité au moment des élections municipales, l'on notera que la question du territoire fut, ici aussi, loin d'être anodine ${ }^{63}$. En premier lieu, parce que dans un paysage de bocage à l'habitat émietté, la représentation au sein du conseil passait par l'extrême attention que ses habitants accordaient à ce que toutes les parties de la commune se sentent représentées par l'un des leurs. Il est ainsi troublant de constater que la répartition des sièges à l'assemblée, même lorsque deux listes s'affrontaient, essayait de répondre à cet impératif-là. À Mahalon, entre 1831 et 1852 , lorsqu'un conseiller municipal décédait, se retirait de la compétition ou était battu, son successeur, soit parce qu'il était son fils - les dividendes de la reproduction politique par accumulation d'un capital social et municipal -, soit parce qu'il appartenait au même quartier ou au même hameau, se devait d'incarner, par sa présence au sein de l'assemblée, cette portion de la circonscription. En tant que prescriptrice d'un territoire politique communal, l'élection municipale fut, en second lieu, dès la monarchie de Juillet, un de ces moments exceptionnels pendant lequel la collectivité pouvait éprouver son unité. Mais, tandis que le suffrage censitaire avait interdit aux hameaux les plus pauvres d'être représentés puisque leurs habitants ne pouvaient prétendre figurer sur les listes des mandants, le suffrage universel permit, au contraire, de rompre avec une topographie électorale mouchetée en unifiant de fait tous les villages. Ce ne fut pas là une de ses moindres conséquences. En éliminant le cens, ce discriminant social et géographique, et en favorisant le synocisme ${ }^{64}$, la République consacra l'existence d'un territoire communal en

63. Pour comparaison, signalons deux études de cas : Mélanie Atrux, «La politisation des campagnes lyonnaises au XIX ${ }^{\mathrm{e}}$ siècle : Collonges-au-Mont-d'Or (Rhône), 1830-1853", Ruralia, n 12-13, 2003, p. 33-64; André Balent, La Cerdagne du XVII au XIX siècle : la famille Vigo. casa-frontières pouvoir, Canet, Trabucaire, 2003, p. 272-283.

64. À la manière de ce qui se déroula dans les cités de la Grèce ancienne. Cf. Pierre Vidal-Naquet et Pierre Lévêque, Clisthène l'Athénien, Paris, Les Belles Lettres, 1964; Christian Meier, La naissance du 
propre (ce qui n'était pas le cas sous le régime censitaire dans la mesure où des électeurs forains pouvaient participer au nom des contributions qu'ils acquittaient), dissocié de l'espace paroissial, que l'urne du chef-lieu, qui matérialisait la fusion des suffragants et donc des écarts, incarnait momentanément. En forçant le trait, on soulignera que l'unité des cortèges d'avril 1848, dans ce qu'elle révéla d'un "peuple-totalité» ${ }^{65}$, se réfracta trois mois après à l'échelle locale : dans cette participation des hommes et des hameaux à la production d'une symbiose communautaire.

\section{- Une extrême plasticité des espaces électoraux}

Cette observation est indexée à l'hypothèse selon laquelle l'élection étant envisagée comme une adaptation à des règles du jeu dans un cadre imparti ${ }^{66}$ la commune, en l'occurrence -, elle impose une reconfiguration des rapports sociaux dont la seule objectivation ne rend qu'imparfaitement compte. Plus qu'une simple actualisation des relations sociales, l'élection fut, en effet, un «moment»-d'autant plus singulier que les agents en firent eux-mêmes une parenthèse singulière - que le chercheur peut chercher à isoler pour en rendre compte... quand bien même ses résultats accréditent souvent l'immuabilité apparente d'un pouvoir local aux mains de ploutocraties rurales. Si chaque consultation fabriqua un marché démocratique pétri de transactions individuelles et collectives, le moment électoral, en tant que créateur et révélateur des tensions et des enjeux communaux, ne saurait être réductible à une addition d'actes d'agents foncièrement intentionnalistes dont l'historien pourrait retracer a posteriori parcours et stratégies eu égard à leur position économique ou à leur statut à l'intérieur de la collectivité. Les renversements d'alliance entre deux scrutins, à quelques semaines d'intervalle lorsqu'une élection était annulée, nous l'auront appris incidemment. Prenons un exemple. Ça barda en juillet 1848 à Nizon tout près de Pont-Aven. Ici aussi, le renouvellement du conseil municipal attisa bien des convoitises. En lice, le comte Cyprien Hersart de La Villemarqué entendit profiter de l'occasion pour s'installer à la tête de l'assemblée et renouer, après des années de bouderie légitimiste, avec la tradition de l'encadrement notabiliaire. Le cidre coula à flots si l'on se réfere aux protestations et à l'enquête qui fut diligentée à la suite de la consultation. Deux camps s'étaient affrontés : d'un côté, celui du maire sortant Jean Daniélou, un paysan-propriétaire doté de 35 hectares et qui figurait depuis 1832 parmi les dix plus imposés de sa commune. De l'autre, celui des frères La Villemarqué tellement anxieux de ne pas réussir leur coup qu’ils se postè-

politique, Paris, Gallimard, 1995, p. 71-106; Françoise Ruzé, Délibération et pouvoir dans la cité grecque de Nestor à Socrate, Paris, Publications de la Sorbonne, 1997, p. 369-373; Violaine Sebillotte Cuchet, Libérez la patrie! Patriotisme et politique en Grèce ancienne, Paris, Belin, 2006, p. 191-194.

65. Pierre Rosanvallon, Le peuple introuvable..., op. cit., p. 39 et p. 53-55.

66. $C f$., sur ce point, les préalables épistémologiques avancés par Laurent Quéro et Christophe Voilliot, «Du suffrage censitaire au suffrage universel. Évolution ou révolution des pratiques électorales?", Actes de la recherche en sciences sociales, n 140, décembre 2001, p. 34. 
rent à l'entrée de la mairie afin de contrôler les bulletins de ceux qui s'y rendaient. Au terme du dimanche électoral, près de $67 \%$ des 305 mandants de Nizon avaient déposé un billet. Seuls 10 des 77 villages de la circonscription n'avaient pas été représentés dans l'urne faute de votants. Le résultat sembla sans appel : avec un peu plus de $60 \%$ des voix, les candidats emmenés par le châtelain avaient tous été nommés au premier tour. C'était sans compter sur la protestation du "parti» battu qui vint ternir le scrutin... et déboucha finalement sur son annulation. L'on revota donc le 8 octobre. 256 électeurs se mobilisèrent, soit une participation de $79,25 \%$ et une augmentation (classique dans ce genre de situation) de $27 \%$ du nombre des présents. Deux listes s'affrontèrent derechef et le camp des La Villemarqué l'emporta sans coup férir. Rien de plus simple en apparence. L'analyse micro-historique de cette affaire ne laisse pourtant pas d'étonner. Car, par-delà la bipolarisation classique, l'affrontement entre les deux "partis » ne fut pas un affrontement entre les mêmes candidats. En un peu plus de deux mois, certains colistiers étaient passés d'un camp à l'autre sans que l'on puisse élucider les raisons de ces transferts, tandis que le maire sortant avait délégué à son fils le soin de conduire la bataille. La configuration politique s'était métamorphosée en quelques semaines. L'élection n’avait donc pas permis à deux factions - ainsi qu'on les retrouve par exemple dans le Quercy de François Ploux ${ }^{67}$ - de trouver de quoi se ressouder dans l'arène municipale. On ne peut plus fréquents, ces retournements de situation ont de quoi désarçonner dans une Basse-Bretagne où le clientélisme ${ }^{68}$ n'existait guère; ils expriment surtout l'extrême élasticité des alliances (de circonstance) que l'inconstance des comportements individuels et/ou collectifs ne cessa de provoquer.

Conclure sur l'élection au village... Mais comment faire tant subsistent des interrogations, des zones d'ombre et des différences d'appréciation? Comment faire si, après avoir entrepris de dénaturaliser la version idéalisée d'un processus linéaire qui conduirait l'électeur en campagnes du statut de non-politisé à celui de politisé - un citoyen intégré par et pour un ordre démocratique -, l'on ne cherchait pas à emprunter des chemins de traverse au risque qu'ils épaississent un peu plus cette opération électorale dont la clarté fut l'une des ambitions d'un pouvoir démocratique soucieux de prouver ainsi sa légitimité. Qu'il s'agisse, par exemple, des pratiques informelles ${ }^{69}$

67. François Ploux, Guerres paysannes en Quercy. Violences, conciliations et répression pénale dans les campagnes du Lot (1810-1860), Paris, La Boutique de l'Histoire, 2002, p. 111-115.

68. La Bretagne n'était pas la Corse ou le Midi... Cf. Jean-Louis Briquet, «Les "primitifs" de la politique. La perception par les élites du vote en Corse sous la III ${ }^{e}$ République», Politix, n 15,1991 , p. 32-47; Frédéric Monier, La politique des plaintes. Clientélisme et demandes sociales dans le Vaucluse d'Édouard Daladier (1890-1940), Paris, La Boutique de l'Histoire, 2007, en particulier p. 49-55.

69. Philippe Aldrin, «S'accommoder du politique. Économie et pratiques de l'information poli- 
qui environnèrent les scrutins ou de la nature d'une démocratie villageoise - entre simulacre ${ }^{70}$ et investissements partisans ${ }^{71}$ - dont d'aucuns soulignent la fonction d'amortisseur dans l'atténuation de certaines crises politiques ${ }^{72}$, l'on constatera aisément que "l'élection au village» (comme objet) résiste à de consensuels entendements. L'on soulignera, par exemple, que sa mise en forme textuelle, qui fut profuse (des procès-verbaux à la prose conflictuelle incluse dans un corpus protestataire extrêmement volumineux), mériterait aussi d'être prise en compte pour ce qu'elle fut : un jeu d'écriture. En cas de conflit, la narration électorale, qui conditionna le regard des représentants de l'État sur cette activité démocratique, fut cantonnée par ces derniers dans le seul registre de la fièvre passagère. Conjugaison de divers discours, elle pourrait devenir autre chose que ce pour quoi ils la tinrent - et nous la tenons - le plus fréquemment : une juxtaposition de pratiques scripturales spécifiquement électorales dont une analyse appropriée permettrait de cerner davantage le feuilletage des strates d'identification de l'acte de vote par ceux qui s'en firent ses auteurs.

Laurent Le Gall est maître de conférences à l'Université de Bretagne Occidentale (CRBC EA 4451)

tique", Politix, n 64, 2003, en particulier p. 187-191. Cf. aussi Michel Offerlé, François Ploux et Laurent Le Gall [dir.], La politique informelle (XIXe-XXIe siècle), Rennes, Presses universitaires de Rennes, à paraitre en 2012 .

70. Cf. l'excellente analyse de Claude Karnoouh, «La démocratie impossible. Parenté et politique dans un village lorrain ", Études rurales, n ${ }^{\circ}$ 52, octobre-décembre 1973, p. $24-56$ (texte paru sous une forme remaniée dans l'ouvrage d'Hugues Lamarche, Susan Carol Rogers et Claude Karnoouh, Paysans, femmes et citoyens. Luttes pour le pouvoir dans un village lorrain, Le Paradou, Actes Sud, 1980, p. 180 210).

71. Cf. les analyses de Laird Boswell qui remettent en question la notion de tradition politique par transferts successifs de voix : Le communisme rural en France. Le Limousin et la Dordogne de 1920 à 1939, Limoges, Presses universitaires de Limoges, 2006 ( $1^{\text {re }}$ édition 1998); et, en contrepoint, les analyses de Dominique Danthieux qui écrit à propos des ruraux de la Haute-Vienne : «En outre, l'égalitarisme communiste satisfait à la vieille aspiration à la République des paysans qui s'exprimait déjà sous la Seconde République. Enfin, la conversion au communisme consacre l'aboutissement d'un processus de politisation marqué par la progressive radicalisation d'une partie de la paysannerie limousine ", $L e$ département rouge. La formation d'une identité politique dans le département de la Haute-Vienne de la fin du XIXe siècle aux années 1930, Thèse d'histoire sous la direction de Jean-Paul Brunet, Université Paris 4, 2002, volume 1, f 441 (parution sous le titre : Le département rouge. République, socialisme et communisme en Haute-Vienne, 1895-1940, Limoges, Presses universitaires de Limoges, 2005).

72. Robert O. Paxton, Le temps des chemises vertes. Révoltes paysannes et fascisme rural, 1929-1939, Paris, Le Seuil, 1996, p. 262-266. 